\title{
DÍVIDA PERIGOSA. DIREÇÃO: MARTIN ZANDVLIET. PRODUÇÃO DE LINSON ENTERTAINMENT, WAYPOINT ENTERTAINMENT. ESTADOS UNIDOS: NETFLIX, 2018. MÍDIA DIGITAL.
}

Cassiana Sare Maciel $^{l}$

O uso do passado para perpetuação de paradigmas acerca de uma região, povo ou cultura não é um tema novo. Esse passado, representado através dos recursos do audiovisual, tem uma dimensão bastante fidedigna, catalisando seu potencial de estampar uma realidade sem deixar aparente que se trata de uma narrativa - ao mesmo tempo em que constitui uma importante fonte para o estudo histórico. A combinação entre sentimentalismo e prazer visual característica do melodrama (XAVIER, 2003), por sua vez, aumenta ainda mais seu poder de transmissão de um discurso, uma vez que são utilizados recursos de identificação e espetáculo que funcionam como uma espécie de pedagogia.

Metodologicamente, de acordo com Marcos Napolitano (2006), há três possibilidades básicas de relação entre a história e o cinema: a história do cinema, a história no cinema e o cinema na História. Sobre as duas últimas áreas, acerca do cinema como produtor de um discurso histórico, fruto de sua época, insere-se esse trabalho. Nesse sentido, duas linhas

${ }^{1}$ Graduanda do curso de História (Licenciatura e Bacharelado) da Universidade Federal do Paraná. Email para contato: cassiana.maciel@gmail.com. Endereço para o Currículo Lattes: http://lattes.cnpq.br/3210157518477759. 
temporais são imperativas à análise: o ano de 2018, contexto de produção, distribuição e recepção de Dívida Perigosa (The Outsider, em inglês), bem como 1954, ano em que se passa a narrativa da produção.

Além disso, é importante o movimento de recuperação da tradição cinematográfica sobre a qual situa-se o filme. Isto é, seus mecanismos melodramáticos e diálogos com outras produções análogas, sejam eles intencionais ou não. A tragédia clássica, habitualmente debruçada sobre dramas de família e conflitos de linhagem, segundo Ismail Xavier (2003), aparece junto de estereótipos que abrigam e ao mesmo tempo simplificam as questões em pauta na sociedade, que é o caso de "o forasteiro", em tradução literal. O filme está situado na tradição de filmes como Avatar, em que uma nova e diferente sociedade é apresentada ao público através dos olhos do personagem principal, construído para gerar identificação com o público. Diferente de Avatar, no entanto, a outra sociedade é o Japão, representado como o "Outro", enquanto o protagonista é estadunidense, espelhando o público não-oriental. Reproduzindo a família Shiromatsu, uma yakuza, a narrativa ainda se passa sobre um lugar comum do ponto de vista do Ocidente, que recebe e representa com fascínio os temas das gangues familiares e da violência como características do Japão.

Nesse sentido, o Orientalismo de Edward Said oferece amparo teórico para a discussão. Quando o pesquisador escreveu sua obra homônima, em 1978, observou e apontou uma longa tradição de estereótipos e discursos historicamente construídos acerca do que genericamente se chama oriente. Sua obra, apesar de debruçada sobre a 
visão dos árabes, pode e deve ser transposta a outras regiões do chamado Oriente, uma vez que sua invenção se dá também sobre outras culturas generalizadas, muitas vezes, como a arábica. Antes de Edward Said, o termo designava uma área de pesquisa que, naturalmente, era também orientalista nos termos do autor.

Portanto, o reconhecimento do Orientalismo imperante, bem como da impossibilidade de evitá-lo, permeia a resenha. O uso da perspectiva de Said conceberá o discurso fílmico enquanto repetidor de uma ampla tradição, que por sua vez não poderá ser satisfatoriamente contraposta na resenha. Mesmo assim, é necessário olhar para o contexto representado por outras óticas e fontes.

Dívida Perigosa ou "O Estrangeiro" conta sua história a partir do ponto de vista de Nick Lowell (Jared Leto), um estadunidense ex-combatente da Segunda Guerra Mundial preso no Japão que divide a cela com Kiyoshi (Tadanobu Asano), um yakuza. Após salvar a vida do companheiro, Lowell é acolhido e empregado dentro da organização.

Logo nas primeiras cenas do filme, o espectador é apresentado a uma realidade hostil e autoritária, permeada de hierarquias, humilhações e disciplina dentro e fora da prisão em que Nick Lowell está. Com cenas de tortura também dentro e fora da instituição, o personagem principal, único ator não-oriental, é apresentado de forma a causar empatia e pena, uma vez que ele aparece inocente e com boas intenções - a saber ter salvado, nos primeiros minutos, a vida de Kiyoshi, cujo nome nem sequer conhecia na ocasião. Essa versão da perda da inocência é confirmada quando, no 
desenrolar do filme, é revelado seu estatuto de ex-combatente da Segunda Guerra. Em outras palavras, percebe-se a versão de um capitão patriota prisioneiro de guerra que perde sua pureza ao entrar em contato com o que aparece como o violento mundo do crime japonês, com a presença de clichês como eventos com lutas de sumô e saquê.

Longe da representação fílmica, yakuza não nomeia qualquer organização criminosa, mas seus integrantes. Esses, que hoje são 40 mil, eram no pós-guerra, época da narrativa, pelo menos quatro vezes esse número (Kaplan e Dubro, 2003). Também distante da hollywoodiana versão japonesa da máfia, a associação dos yakuza carrega uma história de mais de 400 anos, em uma teia complexa de grupos que exerceram e exercem uma ampla gama de atividades.

Ambientado em um Oriente a ser possuído pelo protagonista, a trama perpassa a necessidade de Lowell de honrar seu acolhimento ao clã, que em nenhum momento aparece enquanto um elemento histórico fruto da exclusão social japonesa. Ao longo do filme, aparecem uma série de desafios, no formato de estereótipos - como a hostilidade e violência inicialmente contrastantes com Lowell -, superados como espécies de rituais para uma versão melhorada dos próprios japoneses que representavam aquele meio. Isso é demonstrado com a conclusão da narrativa, que evidencia uma versão final do estadunidense como maior manifestação de honra do que Orochi, membro da família que torna-se vilão ao trair o clã e acaba decepado por Lowell. Do outro lado, o 
ex-soldado chega a cortar o dedo mindinho (Yubitsume) como prova de sua lealdade e é reverenciado pelos inimigos por sua honra na cena final.

Apesar de constituir uma prática da tradição dos yakuza - já que dificulta a empunhadura da espada e aumenta a dependência do grupo - o Yubitsume é, junto das tatuagens, o estereótipo mais citado a respeito dessas pessoas, que no filme aparece sob outro nome. De acordo com Kaplan e Dubro (2003), desde a primeira produção cinematográfica sobre os yakuza esse ritual é representado. Realizado pelo expatriado, ele contrasta especificamente com a postura de Orochi, com a construção de uma progressão que implica justamente na superioridade do forasteiro, para quem há pouco toda a violência era representada como hostil.

Além de situado na tradição do forasteiro que se adapta e abraça o diferente que outrora combatera - da qual pertence também o semelhante $O$ Último Samurai (2003) - o filme também repete o padrão descrito por Said (1990: 38) a respeito do papel das mídias que "forçaram a informação para dentro de moldes cada vez mais padronizados", sendo uma obra que fala mais sobre a tradição ocidental de pensar o Japão e o Oriente de modo geral do que sobre seu conteúdo em si. Ainda de acordo com ele (1990: 291), outro padrão observado nos filmes produzidos sobre árabes que se repete no caso de Dívida Perigosa é o da falta de individualidade. Em outras palavras, o único personagem que contém uma longa história capaz de gerar empatia é o próprio protagonista, o forasteiro, enquanto todos os outros são realmente "Outros", representados como frios e misteriosos, sem características distintivas entre si. 
Cadernos de Clio, Curitiba, v. 12, $n^{\circ} .1,2021$

Sendo The Outsider um discurso estadunidense a respeito de uma organização que só ganhou atenção na segunda metade do século XX por sua notoriedade e influência em vários países, ele também é político. Reduzindo os seus integrantes a uma massa dotada das mesmas características amorfas, ele o faz sobretudo a partir do lugar privilegiado de um presente que constrói o passado. De acordo com Kaplan e Dubro (2003), à época representada no filme, na realidade de reconstrução japonesa no pós-guerra, os yakuza foram recrutados pelo governo para formar um exército de 28 mil pessoas a fim de integrar a segurança do presidente Eisenhower, cuja visita foi marcada por conturbações. Ainda de acordo com os autores, em 1983, os yakuza estavam presentes na agenda da comissão dedicada ao crime organizado do então presidente Ronald Reagan, enquanto boa parte da inteligência era dedicada a esse respeito (um terço da agenda de 1984). Em suma, entre 1960 e 1984 os yakuza passaram de seguranças do presidente estadunidense à ameaça internacional.

Além de retratar um grupo diverso e amplo histórica e culturalmente sob a ótica definida a partir da década de 1980, o que o filme parece fazer, colocando um estadunidense como atuante no contexto de participação dos yakuza nos Estados Unidos, é também reparar ou maquiar o antigo desconhecimento sobre a atuação do grupo no país, que segundo Kaplan e Dubro se estendeu até a mesma década.

Com séculos de tradição, os yakuza não eram o grupo violento do filme. Ainda em 1986, Kaplan e Dubro compilaram, em um de seus capítulos, o descontentamento dos integrantes da organização com a 
crescente violência no modus operandi dos clãs. Segundo Kakuji Inagawa (apud Kaplan e Dubro, 2003: 325), quem fizesse parte da organização deveria respeitar a moral e as regras, o que à época ele via sendo deixado de lado gradualmente em função de uma violência desenfreada que se delineava. É de se destacar também, portanto, o anacronismo na representação de 1954, que trata os grupos como praticantes de uma violência que se esgota em si mesma.

Assim, o filme encaixa-se na típica produção ocidental sobre oriente definida por Said, que por um lado não se preocupa com as pessoas representadas na obra e, por outro, reforça e estimula o medo e estranhamento em relação ao retratado, que parece atemporal para encontrar identificação no público e sedimentar noções preconcebidas. Diferente da representação árabe nos filmes, no entanto, as representações estadunidenses sobre os yakuza parecem ser produzidas uma sobre a outra, repetindo os estereótipos integralmente.

Produzido em versão diferente da inicialmente roteirizada, o filme foi pensado para ser dirigido por Takashi Miike, famoso diretor japonês. De um grande projeto a ser distribuído pela Warner Bros., a produção foi distribuída através de serviços de streaming, com diretores e atores diferentes do planejado. Em manifestação na internet já apagada, o diretor Aaron Stewart-Ahn declarou ter tido acesso ao roteiro original, cuja segunda página mencionava "os pênis maiores dos causasianos". Não é de se espantar, com sustentação nos conteúdos e discursos acima expostos, que se trate de uma informação verdadeira, em plena conformidade com o 
orientalismo contido na produção. Apesar de não poder ser checada, o elemento serve apenas como pormenor no amplo palco de estereótipos exposto.

Apesar de o inglês falado ao longo do filme ser gradualmente substituído pelo japonês sob exigência da família Shiromatsu, os diálogos entre Lowell e Miyu, seu par romântico, são sempre em inglês. Assim, como se houvesse a intenção de transpor a tradição fílmica já conhecida do Ocidente em uma espécie de mistura entre $O$ Poderoso Chefão e $O$ Último Samurai, um bloco de produção não-oriental é enxertado em uma realidade que era completamente diferente disso.

Em uma espécie de "Jornada do Herói”, o espectador é conduzido por uma série de lugares comuns na visão ocidental sobre o oriente, com percalços marcados pelo que tenta representar um choque cultural, até o triunfo maior daquele que chegara há pouco e tornou-se chefe do grupo. $\mathrm{O}$ resultado não poderia ser diferente: um puro suco de Orientalismo, que é capaz de despertar a curiosidade mas que tem em si um potencial mais destrutivo do que construtivo em função dos recursos melodramáticos que também servem ao Orientalismo no filme.

A série de elementos descontextualizados e estereotipados, para transpor a conhecida narrativa de máfia para um Japão com yakuza generalizados, demandariam mais páginas para serem satisfatoriamente contemplados em seus diferentes contextos e processos históricos.

Mais do que abrigar questões em pauta na sociedade, Dívida Perigosa simplifica e mente. O filme comunica, a todo momento, clichês 
do que os diretores imaginaram ser o Japão na década de 1950 com base em pouca ou nenhuma pesquisa. Em suma, a falta de cuidado não é mais grave do ponto de vista da acurácia histórica, mas do produto cultural que serve de ilustração para um Oriente como invenção do Ocidente.

\section{Referências}

KAPLAN, David. DUBRO, Alec. Yakuza: Japan's criminal underworld, expanded ed. California: University of California Press, 2003.

KROLL, Justin. Espinosa in talks to direct 'The Outsider'. Variety, 01 mar. 2012

Disponível

em: https://variety.com/2012/film/news/espinosa-in-talks-to-direct-the-outsider1118050953/. Acesso em: 12 fev. 2021.

MCNARY, Dave. Tom Hardy Stars in 'The Outsider' With Takashi Miike Directing. Variety, 06 jun. 2013. Disponível em: https://variety.com/2013/film/news/tom-hardy-stars-in-the-outsider-with-ta kashi-miike-directing-1200493822/. Acesso em: 12 fev. 2021.

NAPOLITANO, Marcos. "A História depois do papel”. In: PINSKY, Carla. et al. Fontes Históricas. São Paulo: Contexto, 2008. pp. 235-289.

ROLLI, Bryan. Jared Leto's Netflix film 'The Outsider' draws whitewashing accusations. Daily Dot, 24 fev. 2018. Disponível em: https://www.dailydot.com/upstream/jared-leto-the-outsider-whitewashing/. Acesso em: 12 fev. 2021.

SAID, Edward. Orientalismo: o Oriente como invenção do Ocidente. São Paulo: Companhia das Letras, 1990.

XAVIER, Ismail. "Melodrama ou a sedução da moral negociada". O olhar e a cena: melodrama, Hollywood, Cinema Novo, Nelson Rodrigues. São Paulo: Cosac \& Naify, 2003. pp 85-99. 
Cadernos de Clio, Curitiba, v. 12, $\mathrm{n}^{\circ} .1,2021$

Recebido em: 06/05/2021 Aceito em: 19/10/2021 